\title{
Implicit False Memory in the DRM Paradigm: Effects of Amnesia, Encoding Instructions, and Encoding Duration
}

\author{
Ilse Van Damme and Géry d'Ydewalle \\ University of Leuven
}

\begin{abstract}
Recent studies with the Deese/Roediger-McDermott (Deese 1959; Roediger \& McDermott, 1995) paradigm have revealed that amnesic patients do not only show impaired veridical memory, but also diminished false memory for semantically related lure words. Due to the typically used explicit retrieval instructions, however, this finding may reflect problems at encoding, at recollection, or both. Therefore, the present experiments examined implicit as well as explicit false memory in patients suffering from Korsakoff's syndrome and controls. In Experiment 1, encoding instructions either focused on remembering individual list words, or on discovering semantic relationships among the words. In Experiment 2, different presentation durations were used. Results emphasize the distinction between automatic and intentional retrieval: Korsakoff patients' veridical and false memory scores were diminished when explicit recollection was required, but not when memory was tested implicitly. Encoding manipulations only significantly affected veridical memory: Priming was reduced with thematic encoding, and explicit retrieval was facilitated when given more study time.
\end{abstract}

Keywords: amnesia, false memory, gist memory, implicit memory, DRM paradigm

During the last decade, cognitive psychologists have started to look into the distortion of memory and the creation of "false" memories not only in healthy individuals, but also in specifically targeted groups, such as older people (e.g., Dehon, 2006), patients suffering from Alzheimer's disease (e.g., Budson, Sullivan, Daffner, \& Schacter, 2003), amnesic patients (e.g., Schacter, Verfaellie, \& Koutstaal, 2002), patients suffering from schizophrenia (e.g., Moritz, Woodward, Cuttler, Whitman, \& Watson, 2004), patients with frontal lobe damage (e.g., Budson et al., 2002; Melo, Winocur, \& Moscovitch, 1999), and so forth. The paradigm most often used for this type of research is the Deese/Roediger-McDermott (DRM) paradigm, developed by Deese in 1959, and revived by Roediger and McDermott in 1995. In this paradigm, participants study lists of words that are all semantic associations to a

Ilse Van Damme and Géry d'Ydewalle, Department of Psychology, University of Leuven, Leuven, Belgium.

The present research was supported by a grant from the Research Foundation-Flanders (FWO), of which Ilsc Van Damme is a PhD Fellow. It was also supported by Grant P6/29, to Géry d'Ydewalle, from the Interuniversity Attraction Poles program of the Belgian federal government. Parts of this paper were presented at the Joint Meeting of the Experimental Psychology Society and the Belgian Association for Psychological Sciences, Cardiff, Wales, April 2007; at the fifteenth annual conference of the European Society for Cognitive Psychology, Marseille, France, August, 2007; and at the Annual Meeting of the Belgian Association for Psychological Sciences, Leuven, Belgium, May, 2008. We thank the psychiatric centers Broeders Alexianen (Boechout and Tienen), De Ent (Torhout), Sint-Amandus (Beernem), Sint-Amedeus (Mortsel), Sint-Kamillus (Bierbeek), and Ziekeren (Sint-Truiden) for coordinating the participation of their patients in the present experiments. We also thank Loes Stukken and Sabrina Vinck for their help with finding and testing control participants for Experiment 2.

Correspondence concerning this article should be addressed to Ilse Van Damme, Department of Psychology, University of Leuven, Tiensestraat 102, B-3000 Leuven, Belgium. E-mail: ilse.vandamme@psy.kuleuven.be critical, but nonpresented "lure word." False memory is then measured as the tendency to recall and/or recognize the nonpresented lure words, and has been shown to occur with a probability similar to the probability of recalling/recognizing actually presented list words.

When amnesic patients are tested with the DRM paradigm, they demonstrate reduced levels of false recognition and different patterns of false recall as compared to memory-intact controls (e.g., Koutstaal, Verfaellie, \& Schacter, 2001; Melo et al., 1999; Schacter, Verfaellie, \& Anes, 1997; Schacter, Verfaellie, Anes, \& Racine, 1998; Schacter, Verfaellie, \& Pradere, 1996; Verfaellie, Schacter, \& Cook, 2002). However, there are two alternative explanations to account for these findings. First, in line with theories of amnesia referring to deficient relational or contextual processing (e.g., Cohen, Poldrack, \& Eichenbaum, 1997; Johnson \& Chalfonte, 1994), diminished false recognition might be due to defective encoding of the relationships between study items. Or in other words, as argued by Verfaellie et al. (2002), amnesic patients might be "unable to encode, store or maintain robust gist information in the same way normal participants do" (p. 2365). Alternatively, patients amnesic diminished false memory might also be attributed to defective retrieval of properly encoded information. After all, memory testing in the DRM paradigm typically comprises explicit retrieval instructions, requiring participants to intentionally remember earlier presented words. As amnesic patients are characterized by problems with the intentional and conscious recollection of information from memory (e.g., Beauregard et al., 1997; Cermak, Verfaellie, Sweeney, \& Jacoby, 1992; d'Ydewalle \& Van Damme, 2007), diminished test performance might reflect defective retrieval, rather than what was actually encoded into memory. Preliminary support for the latter was obtained in Van Damme and d'Ydewalle (2009), where Korsakoff patients syndrome's false recognition rate was significantly lower than controls' when testing was postponed until the end of the experiment, but not when it occurred immediately after each study list. 
Implicit memory differs from explicit memory in that it reflects automatic rather than controlled retrieval of information from the study phase (Graf \& Schacter, 1985). Hence, an implicit false memory test would allow for the investigation of amnesic patients relational encoding capacities without having to consider their explicit recollection deficit. Several studies have shown that implicit false memory, or priming for nonstudied critical lure words, can be obtained in the DRM paradigm (Lövdén \& Johansson, 2003; McDermott, 1997; McKone \& Murphy, 2000; Smith, Gerkens, Pierce, \& Choi, 2002; Tajika, Neumann, Hamajima, \& Iwahara, 2005; Tse \& Neely, 2005; however, see also Hicks \& Starns, 2005; McBride, Coane, \& Raulerson, 2006). For instance, with a word stem completion task, "false priming" reflects the enhanced tendency to complete stems to critical lures related to studied lists, as compared to the baseline completion rate for lures related to nonstudied lists. Important to consider is that such false priming can only occur if the semantic relationships between the study words are properly encoded, whereas veridical priming merely requires adequate encoding of the to-be-studied list words.

As amnesic patients do produce normal priming for studied words in a variety of implicit memory tasks (e.g., Beauregard et al., 1997; Carlesimo, 1994; d'Ydewalle \& Van Damme, 2007; Phaf, Geurts, \& Eling, 2000; Schacter, 1987), the crucial question is whether they will also show preserved (false) priming for critical lures. If so, this would imply that the earlier demonstrated false memory deficit can entirely be attributed to the typically used explicit retrieval instructions. Alternatively, if the patients' false memory continues to be diminished even when tested implicitly, this would point to an inability to process the necessary relational information at study (i.e., an encoding deficit). Verfaellie, Page, Orlando, and Schacter (2005) recently provided evidence in favor of the latter. They presented amnesic patients and controls with eight DRM lists, and subsequently tested memory by means of both implicit stem completion and explicit stem cued recall (either following presentation of all lists in Experiment 1, or following each separate list in Experiment 2). Patients demonstrated intact priming for studied words, but failed to show priming for critical lures. So, whereas veridical memory was impaired only when tested explicitly, false memory was diminished regardless of the retrieval instructions used.

Although Verfaellie et al.'s (2005) results do point to impaired relational encoding in amnesia, some methodological aspects nonetheless hampered an unequivocal conclusion. First, because of overlap between implicit and explicit test stimuli, explicit test performance might have been influenced by previous implicit test performance: In Experiment 1, retrieval instructions were manipulated within-subjects and the same test items were used at both times. In Experiment 2, study materials in the implicit condition were used as baseline materials in the explicit condition. Second and more importantly, the interpretation of priming scores was hindered by large group differences in the baseline completion rates for critical lures (though it should be mentioned that similar results were obtained when baseline completion rates were equated across groups by removing outlying values).

To overcome these limitations, the present experiments tried to replicate the implicit false memory findings by means of a slightly different design and procedure. As in Verfaellie et al. (2005), Experiment 1 comprised a delayed stem completion test, whereas memory was tested immediately after each list in Experiment 2.
The methodology was adapted as follows. In Experiment 1, retrieval instructions were manipulated between-subjects, to avoid any stimulus overlap. Because of the inclusion of a free recall test at the end of the experiment, implicit stem completion could still be presented as an unrelated filler task. In Experiment 2, retrieval instructions were manipulated within-subjects, but materials were counterbalanced as such that study items in one condition did not serve as baseline items in the other. Moreover, when constructing the word lists for both experiments, special attention was given to the baseline completion rates, in order to keep them as low as possible. Finally, in light of Verfaellie et al.'s finding of reduced false priming in amnesia, encoding instructions were manipulated in Experiment 1, and various encoding durations were used in Experiment 2. It was decided to focus exclusively on patients suffering from Korsakoff's syndrome, instead of using a mixed amnesic group, as previous studies occasionally obtained different results for Korsakoff than for non-Korsakoff patients (Schacter et al., 1998; Verfaellie et al., 2002).

\section{Experiment 1}

Phaf et al. (2000) recently demonstrated that elaboration learning is impaired (but not completely eliminated) in Korsakoff patients, particularly when spontaneous initiation of the process is required (see also Butters \& Cermak, 1980; Cermak, Butters, \& Gerrein, 1973; Cermak, Hill, \& Wong, 1998). Hence, because elaborative relational encoding might be necessary to form a representation of the theme of associative DRM lists (cf. Van Damme \& d'Ydewalle, 2009; see also Verfaellie et al., 2005), difficulties with spontaneously initiating such a strategy might have been responsible for the reduced false priming effect in Verfaellie et al. (2005). To examine this proposition, Experiment 1 included two encoding conditions: Instructions at study either focused on remembering individual list words (basic condition), or on discovering the semantic relationship among the words in a list (support condition). The latter was meant to encourage elaborative relational encoding, and was based on the finding of Chan, McDermott, Watson, and Gallo (2005) that focusing on relevant relationships between list words enhances the likelihood of false memory.

Despite diminished spontaneous initiation of elaborative processing, however, Korsakoff patients have been shown to benefit from instructions to do so (Phaf et al., 2000). In addition, they encode and remember both contextual and sequential information up to a similar level as controls, provided that they are given adequate time and support (Van Damme \& d'Ydewalle, 2008). Therefore, patients in Experiment 1 were expected to show more false memory (both implicit and explicit) in the support condition as compared to the basic condition. For controls, on the other hand, no false memory difference between conditions was predicted, as they were expected to spontaneously adopt a "thematic encoding" strategy. Nevertheless, both participant groups were predicted to show diminished veridical priming (i.e., priming for studied list words) in the support condition, as instructions encouraged them to focus on the meaning shared by the words, rather than on the words themselves.

\section{Method}

\section{Participants}

Pilot data for constructing word lists and selecting target items were collected from 65 volunteering third-year psychology stu- 
dents. Forty-eight patients suffering from Korsakoff's syndrome and 48 healthy controls took part in the actual experiment.

Korsakoff patients (42 men and 6 women) were residents from seven chronic care facilities in Belgium. Their mean age was 55 years (range 42 to $73, S D=7.4$ ) and they had an average of 11 years of formal education (range 6 to $17, S D=2.3$ ). All patients met the criteria for the Diagnostic and Statistical Manual for Mental Disorders Alcohol-Induced Persisting Amnesic Disorder (4th ed., [DSM-IV]; American Psychiatric Association, 1994) and the criteria for the Korsakoff syndrome as described by Kopelman (2002). Neuropsychological assessment data revealed memory impairments in all patients and executive function deficits in most of them. For 13 patients, scores on the Auditory Verbal Learning Test (AVLT; Miatton, Wolters, Lannoo, \& Vingerhoets, 2004; Rey, 1964) and a selection of relevant executive function scores are provided in the Appendix. Additional information is available on request. The healthy and volunteering controls (also 42 men and 6 women) were matched as closely as possible to the patients on the basis of age, gender, education, and (former) vocation. They had a mean age of 54 years (range 40 to $71, S D=7.6$ ) and an average of 12 years of formal education (range 6 to $17, S D=2.1$ ). None of them showed signs of any memory problems.

\section{Materials}

Study lists. The materials used in the study and test phases of Experiment 1 consisted of 16 lists of 16 words. In each list, 15 words were to be presented for study and 1 word (i.e., the critical lure) was not. Following McKone and Murphy (2000), new lists were created to ensure that each critical lure met the requirements for use with stem completion tasks (cf. Graf \& Schacter, 1985).

All critical lures were at least five letters long and had distinct three-letter stems, with at least 8 to 10 possible completions. To avoid excessively high baseline completion rates, a pilot study was carried out to select the critical lures for the present experiment. A list of 30 lure candidates was given to 28 third-year psychology students, who were instructed to complete each stem with the first word that came to mind. Only lures with an unprimed target completion rate of less than $36 \%$ were maintained. Four words were additionally excluded because it was too difficult to find sufficient associations to constitute the corresponding word lists and/or because they showed too much (semantic or orthographic) overlap with other lists or lures. Sixteen critical lures remained to be used for list construction.

Based on Dutch word association norms (de Groot, 1980; de Groot \& de Bil, 1987; Lauteslager, Schaap, \& Schievels, 1986; van der Made-van Bekkum, 1973; van Loon-Vervoorn \& van Bekkum, 1991), 15 strong associations to each critical lure were selected to constitute the corresponding study list. We made sure that none of the associations had the same three-letter stem as any of the lures. Words within a list were ordered by association frequency, with the strongest associations occurring first. If multiple-norm studies were used, the order of the words was based on the most recent work. Three of the lists were derived from the materials in Van Damme and d'Ydewalle (2009), five lists were created for critical lures that were translated from Stadler, Roediger, and McDermott (1999), and eight entirely new lists were developed by the first author.

One word from each study list was selected to be the list target. This word satisfied the stem completion requirements (i.e., having at least five letters and a distinct three-letter stem with at least eight different completions), and was not allowed to appear in either the first two or last two positions of the list (cf. McKone \& Murphy, 2000). A second pilot study was carried out to match these list targets to the critical lures on word frequency as well as baseline completion rate. This was done as follows. First, the two or three words (with at least five letters and multiple-stem completions) with word frequencies closest to the frequency of the lure were selected from each list. Next, 37 third-year psychology students completed the stems of the selected words with the first word that came to mind. Finally, for each list, the word with the baseline completion rate closest to the baseline completion rate of the lure was selected. This way, list targets were matched to critical lures on both word frequency ( $M=97$ and 114 occurrences per million, ranges 5 to 365 and 13 to 353 , respectively, with frequencies counting based on the CELEX lexical database of Baayen, Piepenbrock, \& Gulikers, 1995) and baseline completion rate $(M=12 \%$ and $16 \%$, ranges 3 to 27 and 0 to 36 ).

To allow for counterbalancing of studied versus nonstudied materials, the 16 word lists were subsequently divided into two sets of 8 lists. Following McKone and Murphy (2000), these sets were equated by matching both critical lures and list targets as closely as possible on word frequency and baseline completion rate.

Test construction. Stem completion tests contained 32 threeletter stems, presented in a different random order for each participant. The stems originated from 8 studied words (i.e., list targets from the studied lists), 8 words that were semantically related to the studied words (i.e., critical lures from the studied lists), and 16 unstudied distracter words (i.e., 8 targets and 8 lures from the nonstudied set). The latter were included to provide baseline scores, as well as to disguise the relationship between study and test phase and hence to reduce the chance of explicit contamination for participants in the implicit test condition (cf. McKone \& Murphy, 2000). Both study and test lists were visually presented on a Dell laptop, using black uppercase letters in the center of the screen. E-prime was used for the presentation of all materials.

\section{Design}

Encoding instructions (basic vs. supportive) and type of test (explicit vs. implicit) were manipulated between-subjects, creating four conditions to which patients and controls were randomly assigned (ensuring a group size of 12 people each). Item type (critical lure vs. list target) and list status (studied vs. unstudied) were varied within-subjects. In each condition, one set of eight lists was used for study. The remaining set of eight lists was not studied, but was used for construction of the word stem completion test. Each set was used equally often as studied and nonstudied material, counterbalanced over participants and conditions. Within each set, the order of the lists was held fixed.

The experiment comprised three phases. The study phase involved the visual presentation of eight word lists, which were subsequently tested in a stem completion task with either explicit or implicit test instructions. Memory scores were calculated as the proportion of stems completed with target/lures from studied lists, minus the baseline completion rate for target/lures from nonstud- 
ied lists. The last phase of the experiment included a free recall test, followed by a memory strategies questionnaire.

\section{Procedure}

Participants were tested individually. They read and signed an informed consent form, after which instructions for study were shown and read out loud by the experimenter. It was explained that eight lists of 15 words would be presented, and that participants were to read the words out loud and try to remember them. Participants in the basic condition were specifically asked to focus on the list words and to try to remember as many as possible. Participants in the support condition were informed that words within a list would share some common meaning, and were asked to think about how each word related to the other words.

Eight lists were visually presented, at a rate of $2 \mathrm{~s}$ per word. Lists were separated from each other by appearance of an asterisk, which was shown for $5 \mathrm{~s}$. This time interval allowed the experimenter to repeat the encoding instructions, so that Korsakoff patients would not forget what they were supposed to do. After all lists had been studied, instructions for the word stem completion task appeared on the screen. Participants in the explicit test condition were informed that some of the stems would be originating from words they had seen during the study phase, whereas other stems would not. They were asked to complete stems only with words they remembered having seen, or otherwise to leave the stem blank. Participants in the implicit test condition were simply asked to complete each stem with the first word that came to mind. Following McKone and Murphy (2000), it was emphasized that the words used to complete the stems could come from anywhere, as long as they were provided as quickly as possible. Proper names were not allowed, and participants were told that it was acceptable to leave an item blank if nothing popped into mind immediately. Stems were presented one by one on the computer screen, with the experimenter writing down all of the responses.

After finishing the stem completion task, a final free recall test was given: Participants were asked to recall as many of the list words as they could still remember. It was made clear that not the stem completion phase, but the first phase of the experiment was to be considered for this task. No time limit was given. Afterward, as a final stage of the experiment, participants were told that the experimenter had some remaining questions about the stems they had completed. Based on the memory strategies questionnaire developed by McKone and Murphy (2000, p. 95), the following three questions were asked: (a) "What was your general strategy when completing the word stems?"; (b) "Did you deliberately try to complete stems with words you remembered from the study lists?"; and (c) "Did you complete stems with whatever word popped into your head first?"

Of particular interest was whether participants in the implicit test condition would report using explicit retrieval. This was not the case. All healthy controls followed the instructions provided to them, as they responded yes to (2) and no to (3) in the explicit condition, and no to (2) and yes to (3) in the implicit condition. Three of the Korsakoff patients did not remember having studied any lists at all by the end of the experiment, which led them to respond no to (2) and yes to (3) even in the explicit condition. Nevertheless, observational data revealed that the patients did try to complete the stems with words they had seen during the study phase. The strategy to do so was however quite different than the one used by controls: Instead of strategically searching their memory, they simply generated some possible completions (i.e., the first words that came to mind), which were then checked through a recognition process (a "generate-recognize" strategy; e.g., Jacoby, 1998). As a result of such a strategy, five of the patients in the explicit condition even answered yes to both (2) and (3). At the end of the experiment, all participants were fully debriefed.

\section{Results and Discussion}

As free recall performance was most likely contaminated by participants' performance on the preceding stem completion tests, the analyses on these data will not be presented here in full. Nevertheless, the scores obtained offer a good illustration of the severity of the memory impairment of the patients participating in the present study: Whereas healthy controls succeeded in remembering on average 17 out of 120 studied words (i.e., 14\%, or on average 2 words per list) and 3 out of 8 critical lures (i.e., 34\%), Korsakoff patients could only recollect 1 out of 120 studied words (i.e., $1 \%$ ) and 0.30 out of 8 lures (i.e., $4 \%$ ).

Stem completion data are presented in Table 1. Memory scores were obtained by subtracting the proportion of stems completed to targets/lures from nonstudied lists (i.e., the baseline completion rate) from the proportion of stems completed to targets/lures from studied lists (cf. McKone \& Murphy, 2000; Verfaellie et al., 2005). For some lists, a "related"- but noncritical-word was occasionally used as a stem completion instead of the critical lure word itself. Because these related words were all derivatives of the originally chosen lure words, and therefore reflected the gist/theme of the lists to the same extent as the original lures did, they were considered to be false memories too. This way, false memory truly reflected memory for the gist of the lists, rather than the use of a word that was arbitrarily selected by the experimenter. For one list, the related word was in fact used as a stem completion more often than the originally selected critical lure (i.e., naaien [to sew] versus naald [needle]). For another list, the related word was used with approximately the same frequency as the original critical lure (i.e., woedend [angry] versus woede [anger]). In all other cases, however, the related word was used as a stem completion only once or twice in the whole sample. All false memory analyses reported in this section were based on loose scoring criteria, including these related words. Nevertheless, analyses including only the critical lures that were selected prior to the experiment revealed equivalent results.

As can be seen in Table 1, baseline completion rates were low and similar for list targets and critical lures. In both conditions and under both kinds of retrieval instructions, patients as well as controls correctly completed more targets and lures from studied lists than from nonstudied lists, suggesting significant implicit and explicit veridical and false memory. In what follows, implicit and explicit performance will be considered successively. An alpha level of .05 was used for all statistical tests.

\section{Implicit Stem Completion}

A 2 (Group: Korsakoff patients vs. healthy controls) $\times 2$ (Encoding Condition: basic vs. support) $\times 2$ (List Status: studied vs. unstudied) mixed-factors analysis of variance (ANOVA) on the 
Table 1

Proportions of Stems Correctly Completed to List Targets and Critical Lures by Korsakoff Patients and Control Participants in Experiment 1, as a Function of Encoding Condition, Test Condition, and List Status

\begin{tabular}{|c|c|c|c|c|c|c|}
\hline & \multicolumn{3}{|c|}{ Implicit test } & \multicolumn{3}{|c|}{ Explicit test } \\
\hline & Studied lists & Unstudied lists & Memory score & Studied lists & Unstudied lists & Memory score \\
\hline & $M(M S E)$ & $M(M S E)$ & $M(M S E)$ & $M(M S E)$ & $M(M S E)$ & $M(M S E)$ \\
\hline \multicolumn{7}{|l|}{ List targets } \\
\hline \multicolumn{7}{|l|}{ Korsakoff } \\
\hline Basic & $.39(.05)$ & $.15(.06)$ & $.24(.07)$ & $.41(.04)$ & $.09(.03)$ & $.31(.06)$ \\
\hline Support & $.33(.06)$ & $.19(.06)$ & $.15(.08)$ & $.31(.06)$ & $.03(.02)$ & $.28(.07)$ \\
\hline \multicolumn{7}{|l|}{ Control } \\
\hline Basic & $.45(.04)$ & $.13(.03)$ & $.32(.06)$ & $.49(.06)$ & $.06(.03)$ & $.43(.06)$ \\
\hline Support & $.29(.05)$ & $.17(.03)$ & $.13(.06)$ & $.54(.05)$ & $.06(.02)$ & $.48(.05)$ \\
\hline \multicolumn{7}{|l|}{ Critical lures } \\
\hline \multicolumn{7}{|l|}{ Korsakoff } \\
\hline Basic & $.27(.05)$ & $.21(.04)$ & $.06(.05)$ & $.22(.04)$ & $.06(.03)$ & $.16(.05)$ \\
\hline Support & $.29(.04)$ & $.21(.04)$ & $.08(.07)$ & $.24(.05)$ & $.04(.02)$ & $.20(.07)$ \\
\hline \multicolumn{7}{|l|}{ Control } \\
\hline Basic & $.27(.05)$ & $.14(.03)$ & $.14(.07)$ & $.43(.05)$ & $.05(.03)$ & $.38(.05)$ \\
\hline Support & $.31(.03)$ & $.21(.05)$ & $.10(.07)$ & $.41(.04)$ & $.01(.01)$ & $.40(.03)$ \\
\hline
\end{tabular}

Note. Memory scores were obtained by subtracting the proportion of stems completed to targets/lures from unstudied lists (i.e., the baseline completion rate) from the proportion of stems completed to targets/lures from studied lists.

completion rates to list targets revealed a significant main effect of List Status, $F(1,44)=35.88, M S E=.029, p<.0001, \eta_{\mathrm{p}}^{2}=.45$; confirming the expected veridical priming effect. In line with previous findings of spared implicit memory in amnesic patients, planned comparisons (Dunn) showed this priming effect to be significant for both patients $(M=.19), t(44)=3.92, p=.0003$; and controls $(M=.22), t(44)=4.55, p<.0001$. A significant List Status $\times$ Encoding Condition interaction, $F(1,44)=4.40, M S E=$ $.029, p=.04, \eta_{\mathrm{p}}^{2}=.09$; revealed that veridical priming was less pronounced in the support condition than in the basic condition $(M=.14$ vs. .28$)$ : As expected, both participant groups showed less priming for the individual list words when instructed to pay special attention to whatever meaning the words had in common than when asked to focus on the words themselves (see Table 1). Nevertheless, priming was statistically significant in both conditions (Tukey; basic: $p<.0001$, support: $p=.04$ ).

The only significant effect revealed by the same $2 \times 2 \times 2$ analysis of variance on the completion rates to critical lures was the main effect of List Status, $F(1,44)=8.70, M S E=.026, p=$ $.005, \eta_{\mathrm{p}}^{2}=.17$. Hence, significant priming for critical lures was obtained. No effects of Encoding Condition were found (all $F \mathrm{~s}$ around 1). Also, contrary to Verfaellie et al. (2005), the Group $\times$ List Status interaction did not turn out to be significant, $F(1$, $44)=0.51, M S E=.026, p=.48$; pointing to similar implicit false memory in both participant groups. However, planned comparisons (Dunn) revealed that priming for critical lures was only significant for controls $(M=.12), t(44)=2.59, p=.01$; but did not reach statistical significance for Korsakoff patients $(M=.07)$, $t(44)=1.58, p=.12$. As can be seen in Table 1, this could mainly be attributed to higher baseline completion rates for patients than for controls in the basic condition. Nevertheless, to investigate whether the absence of a significant group difference might not be due to a lack of power, a post hoc power analysis was carried out on the data using the $\mathrm{G}^{*}$ Power 3 software (Faul, Erdfelder, Lang,
\& Buchner, 2007). Given the sample size of 48 participants and an alpha level of .05 , the power to detect a medium-sized interaction effect was .77. Moreover, compromise and criterion analyses revealed that to obtain a power level of .95 , the alpha level needed to be set on .28. As the $p$-value of the interaction effect was .48 , this would still imply a nonsignificant result, and hence, no group difference in implicit false memory.

\section{Explicit Stem Completion}

A Group $\times$ Encoding Condition $\times$ List Status ANOVA on the list target completion rates revealed significant main effects of Group, $F(1,44)=7.72, M S E=.019, p=.008, \eta_{\mathrm{p}}^{2}=.15$; and List Status, $F(1,44)=148.69, M S E=.023, p<.0001, \eta_{\mathrm{p}}^{2}=.77$; which were involved in a significant Group $\times$ List Status interaction, $F(1,44)=6.45, M S E=.023, p=.01, \eta_{\mathrm{p}}^{2}=.13$. Pairwise Tukey's tests revealed this interaction to be due to a significant group difference in the completion rates to studied targets $(M=$ .52 vs. $.36, p=.003$ ), whereas there was no significant group difference in the completion rates to unstudied targets (i.e., baseline completion). The difference between studied and unstudied targets was, nevertheless, significant for both patients and controls (both $p$ s $<.0001$ ). So, surprisingly, although veridical cued-recall was shown to be higher for controls than for patients, significant memory scores were obtained in both groups. The relatively high score for the patients could most likely be attributed to the use of a generate-recognize strategy, in which words that popped into mind were checked through recognition (e.g., Jacoby, 1998).

The same ANOVA on the critical lure completion rates revealed significant main effects of Group, $F(1,44)=11.61, M S E=.014$, $p=.001, \eta_{\mathrm{p}}^{2}=.21$; and List Status, $F(1,44)=108.18, M S E=$ $.018, p<.0001, \eta_{\mathrm{p}}^{2}=.71$; qualified by a significant interaction between the two, $F(1,44)=14.84, M S E=.018, p=.0004, \eta_{\mathrm{p}}^{2}=$ .25. As for the list targets, this interaction reflected a significant 
group difference in the proportion of correctly completed lures from studied lists $(M=.42$ vs. .23; Tukey, $p<.0001)$, whereas the groups did not differ in their baseline completion rates. So again, significant cued-recall scores were found for both patients $(M=.18$; Tukey, $p=.0002)$ and controls $(M=.39$; Tukey, $p<$ $.0001)$. No significant (main or interaction) effects of encoding condition were obtained (all $F$ s $<1$ ).

\section{Summary}

In the present experiment, a word stem completion task was used to assess both implicit and explicit false memory of patients suffering from Korsakoff's syndrome and memory-intact controls. Patients were expected to show increased false memory following supportive encoding, and both participant groups were expected to show diminished veridical priming due to the focus on relational information in such a condition. Whereas the latter prediction was confirmed, encoding instructions did not exert any effect on the patients' false memory. In addition and contrary to the results of Verfaellie et al. (2005), Korsakoff patients did not differ from controls in implicit false or veridical memory. Both types of memory performance were, however, impaired when it came to explicitly retrieving information from the study phase. Apparently, retrieval instructions influenced the patients' memory for list words and for items reflecting the theme of the lists in similar ways.

The pattern of results points to an important role for explicit recollection processes in explaining earlier findings of reduced DRM false memory in amnesia. The fact that the patients' false priming level did not differ from controls' suggests that they spontaneously adopted the appropriate encoding strategy in both of the present conditions. Nevertheless, as false priming only reached significance for controls, some encoding problem is still within the bounds of possibility. Hence, Experiment 2 was designed to try to replicate the finding of intact false priming and to investigate the effect of another type of support during encoding.

\section{Experiment 2}

Four encoding conditions were used in Experiment 2. Based on evidence that patients suffering from Korsakoff's syndrome need more time to process to-be-remembered materials than control participants do (e.g., Huppert \& Piercy, 1977), list words were presented for either $250 \mathrm{~ms}, 2 \mathrm{~s}$, or $5 \mathrm{~s}$ (i.e., short, standard, long). To explore the possibility that both time and extra support are required to obtain an effect on Korsakoff patients' performance (see Van Damme \& d'Ydewalle, 2008), a condition comprising prolonged study time ( $5 \mathrm{~s}$ ) as well as supportive encoding instructions was also included. Implicit and explicit stem completion tests were administered immediately after each list, as this offered the opportunity to replicate the results of Experiment 1 with the second procedure of Verfaellie et al. (2005).

With respect to veridical memory, predictions were relatively straightforward. No differences were expected between Korsakoff patients and control participants in implicit memory, but patients were expected to perform worse than controls under explicit retrieval instructions. For both groups, explicit memory for list words was predicted to improve when given more time to study. Moreover, it was also predicted that additional study time (5 s) would lift Korsakoff patients' performance up to the level of controls in the standard 2-s condition (cf. Huppert \& Piercy, 1977; Van Damme \& d'Ydewalle, 2008), whereas the patients' performance in the standard condition would be similar to controls' performance in the $250-\mathrm{ms}$ condition. The latter prediction was based on studies showing that amnesic patients are comparable to healthy individuals with weak memory (e.g., after inadequate study time, Meudell \& Mayes, 1984; or after prolonged retention intervals, Woods \& Piercy, 1974).

Considering the effect of study duration on false memory, McDermott and Watson (2001) recently showed that an increase from 20 to $250 \mathrm{~ms} /$ word can boost memory for critical lures due to the automatic build-up of semantic activation, whereas a further increase from $250 \mathrm{~ms}$ to $5 \mathrm{~s}$ rather suppresses (explicit) false memories due to the possibility of extracting additional information and strategically controlled monitoring. Such a decrease, however, has only consistently been shown for free recall, but much less so for false recognition (e.g., Arndt \& Hirshman, 1998; Gallo \& Roediger, 2002; Seamon, Luo, \& Gallo, 1998). Furthermore, the effect of study duration on false memory has been shown to depend on the participant group tested, as both Dehon (2006) and Koutstaal et al. (2001) obtained a decrease in false memory with increasing study time for younger, but not for older adults (probably due to diminished monitoring abilities in the latter group; cf. Dehon \& Brédart, 2004; however, see also Chan \& McDermott, 2007). Hence, as control participants in the present experiment were considered to be "older" rather than "younger" adults, and cued-recall was considered more similar to recognition than to free recall (due to the possible attribution of familiarity to performance), a decrease in explicit false memory with increasing study time was not considered likely. Rather, no effect of study duration on false memory was expected for the control group. For Korsakoff patients, on the other hand, increasing false memory was expected (cf. Schacter et al., 1998), due to the combination of impaired strategic retrieval/monitoring and the automatic build-up of semantic activation induced by the longer presentation durations (see McDermott \& Watson, 2001).

In the implicit stem completion test, increasing false memory with increasing study time was predicted for both participant groups: As implicit retrieval instructions require participants to give whatever word that first comes to mind, strategic monitoring to inhibit false memories is both unnecessary and useless (cf. McKone \& Murphy, 2000; see also Tse \& Neely, 2005), regardless of the study time provided. Based on the results obtained in Experiment 1, no group difference in false priming was to be expected. Based on Verfaellie et al. (2005), however, patients should show significantly less false priming than controls.

\section{Method}

\section{Participants}

Pilot data for selecting the appropriate target items for three new word lists were collected from 20 volunteering adults. Forty-eight Korsakoff patients and 48 control participants took part in the experiment. To take into account the possibility that the effects obtained in Experiment 1 might be related to the patients' history of chronic alcoholism rather than to their amnesic deficit per se, alcoholic as well as healthy control participants were included. 
Korsakoff patients (42 men and 6 women) were residents from three psychiatric institutions in Belgium. Some of them had also participated in Experiment 1, but a period of at least 12 months had passed in-between studies. The patients' mean age was 53 years (range 42 to $68, S D=6.2$ ) and they had an average of 11 years of formal education (range 6 to $16, S D=2.3$ ). They all met the criteria for the DSM-IV Alcohol-Induced Persisting Amnesic Disorder (American Psychiatric Association, 1994) and the criteria for the Korsakoff syndrome as described by Kopelman (2002). All patients showed impaired memory performance on the AVLT (Miatton et al., 2004; Rey, 1964). In addition, they all produced an increased number of perseverative responses on the Wisconsin Card Sorting Test (WCST; Heaton, Chelune, Talley, Kay, \& Curtiss, 1993), and most of them exhibited impaired performance on the Trail Making Test (TMT; Reitan, 1958) and the Controlled Oral Word Association Test (COWAT; Benton \& Hamsher, 1976; Benton, Hamsher, Varney, \& Spreen, 1983). Attention, as measured by the Bourdon-Wiersma Dot Cancellation Test (Van Zomeren \& Brouwer, 1994) was disturbed in approximately half of the patients. Scores on the AVLT, as well as some important executive function scores (reaction times for TMT-Part B, number of appropriate responses on the COWAT, and number of categories and percentage of perseverative errors on the WCST), are presented in the Appendix. Additional data can be acquired from the first author on request.

The group of control participants consisted of 24 individuals with a history of alcoholism (17 men and 7 women) and 24 individuals with no known history of alcoholism (18 men and 6 women). The former were recruited from four psychiatric institutions in Belgium, and had abstained from alcohol for at least 1 month. Both alcoholic and healthy participants were matched as closely as possible to the Korsakoff patients in terms of age $(M=51$ years, range 38 to $67, S D=6.6)$, education $(M=12$ years, range $=6$ to $19, S D=2.8$ ), and (former) vocational levels. None of them had taken part in Experiment 1, and they showed no signs of any memory problems. On the Peabody Picture Vocabulary Test (Dunn \& Dunn, 2005), control participants exhibited significantly higher standard scores $(M=89.9, S D=19.8)$ than patients with Korsakoff syndrome $(M=78.5, S D=18.7)$, $t(94)=2.89, p=.005$; indicating a more extensive (receptive) vocabulary in the former than in the latter group.

\section{Materials}

Study lists. The materials used in the study and test phases of Experiment 2 consisted of 18 lists of 16 words. As in Experiment 1 , each list contained 15 words to be presented for study and 1 critical word that was not to be presented for study.

Fifteen lists were taken from Experiment 1 (with some slight adaptations; 1 list was dropped because it led to virtually no false memories), and 3 additional lists were created in the same way as before. First, based on the pilot study with 28 third-year psychology students (see Experiment 1), three extra critical lures with an unprimed target completion rate of less than $45 \%$ (cf. McKone \& Murphy, 2000) were selected. Next, based on the Dutch word association norms (de Groot, 1980; de Groot \& de Bil, 1987; Lauteslager et al., 1986; van der Made-van Bekkum, 1973; van Loon-Vervoorn \& van Bekkum, 1991), 15 strong associations to each critical lure were chosen to constitute the corresponding study lists (procedure cf. Experiment 1). Finally, a pilot study with 20 adults allowed the selection of one word from each list (with word frequency and baseline completion rate close to the critical lure) to be the list target. As in Experiment 1, list targets and critical lures were at least five letters long and had distinct three-letter stems, with at least eight possible completions.

The 18 word lists were divided into three sets of 6 lists, roughly equated on four dimensions: word frequency and baseline completion rate of the critical lures, the probability of false recall, and the probability of false priming (as obtained in Experiment 1). One set was to be used as study materials in the implicit condition, one set was to be used as study materials in the explicit condition, and one set was to remain unstudied and to serve as baseline in both testing conditions. Assignment of the sets to the three positions was counterbalanced across participants, resulting in six different combinations.

Test construction. For each of the six possible combinations of sets, six stem completion tests were constructed to be used in the implicit retrieval condition (i.e., one corresponding to each study list) and six tests were constructed to be used in the explicit retrieval condition. Each test consisted of 14 three-letter stems, presented in a different random order for each participant. Four stems were considered crucial and could be completed to the list target from the studied list, the critical lure from the studied list, a list target from one of the nonstudied lists (i.e., target distracter), and the critical lure from the same nonstudied list (i.e., critical distracter). In addition, 10 stems were included as filler items, to reduce the possibility that participants would detect a relationship between the study and test phases (cf. Verfaellie et al., 2005). These filler stems did not overlap with any of the stems of the 18 word lists.

Both study and test lists were visually presented on a Dell laptop, using black uppercase letters in the center of the screen. E-prime was used for the presentation of all materials. Whereas the order of words within a study list was held fixed (i.e., according to backward association strength), word stems were randomly presented.

\section{Design and Procedure}

Because presentation duration was manipulated between subjects, participants were randomly assigned to one of four conditions (making sure each group consisted of 12 people). Study words were presented for $250 \mathrm{~ms}, 2 \mathrm{~s}$, or $5 \mathrm{~s}$. With the latter duration, instructions were either standard intentional encoding instructions, or "supportive" instructions, focusing on discovering the theme of each list (cf. Experiment 1). Each participant was tested twice, once under implicit and once under explicit retrieval instructions, the two sessions being separated by at least 4 days. The implicit condition was always administered first, to avoid any suspicion about the nature of the test. Participants were tested individually, and were asked to read and sign an informed consent form before starting the procedure.

The implicit and explicit session both consisted of six study-test trials, preceded by one practice trial. During the study-part of each trial, 15 words were visually presented, and participants were asked to try to remember them. Presentation duration of the words, as well as type of encoding instructions, depended on the condition the participants were assigned to. The test-part of each trial included a stem completion test corresponding to the list that had just been studied, under either implicit or explicit retrieval instructions. During the implicit session, participants were asked to complete 
each stem with the first word that came to mind. To reduce the possibility of explicit contamination, it was mentioned that this task had nothing to do with the preceding study task, and that a memory test would follow at the end of the experiment (which in fact did not come). During the explicit session, participants were told that some of the stems would belong to words from the preceding study list, but most stems would not. They were asked to complete the stems only with words they remembered having seen, or otherwise to leave it blank. To discourage the use of a generate-recognize strategy in Korsakoff patients, it was mentioned that guessing was not allowed.

Study-test trials were presented in a different random order for each participant. At the end of the implicit session, they were asked about their retrieval strategy (cf. questionnaire in Experiment 1). Some people did report that occasionally a word from the study phase popped into mind during stem completion, but none of the participants reported having deliberately used explicit recollection. At the end of the experiment, full explanation was provided.

\section{Results and Discussion}

As in Experiment 1, participants occasionally used noncritical, but strongly related words (i.e., reflecting the theme or gist of the lists) to complete the critical stems. Again, loose scoring criteria were used, so that such completions were considered to be false memories too. Nonetheless, analyses including only those lures that were originally selected revealed equivalent results. For list targets, a stem completion was considered to be a veridical memory only if it matched the word presented for study exactly. Table 2 depicts the mean completion rates of Korsakoff patients and controls, for list targets and critical lures, in all conditions. As in Experiment 1, memory scores were calculated by subtracting the baseline completion rates for nonstudied lists from the proportion of stems completed with targets and lures from studied lists. Because preliminary analyses revealed no differences between control participants with or without a history of alcohol abuse (cf. Verfaellie et al., 2005), results are combined across the two control groups. An alpha level of .05 was used for all statistical tests.

\section{Implicit Stem Completion}

A 2 (Group) $\times 4$ (Encoding Condition) $\times 2$ (List Status) mixed-factors ANOVA on the completion rates to list targets revealed a significant main effect of List Status, $F(1,88)=139.24$, $M S E=.028, p<.0001, \eta_{\mathrm{p}}^{2}=.61$, reflecting veridical priming. As expected, the effect was significant for both patients $(M=.25)$, $t(88)=7.37, p<.0001$; and controls $(M=.32), t(88)=9.32, p<$ .0001 (Dunn). No significant (main or interaction) effects of Encoding Condition were obtained (all $F_{\mathrm{s}} \leq 1$ ).

Similarly, a $2 \times 4 \times 2$ ANOVA on the completion rates to critical lures revealed a main effect of List Status, $F(1$, $88)=29.81, M S E=.042, p<.0001, \eta_{\mathrm{p}}^{2}=.25$; indicating significant false priming. As in Experiment 1, the absence of a Group $\times$ List Status interaction, $F(1,88)=0.03, M S E=.042$, $p=.86$; pointed to similar implicit false memory in both groups. In addition, planned comparisons (Dunn) revealed priming to be

Table 2

Proportions of Stems Correctly Completed to List Targets and Critical Lures by Korsakoff Patients and Control Participants in Experiment 2, as a Function of Encoding Condition, Test Condition, and List Status

\begin{tabular}{|c|c|c|c|c|c|c|}
\hline & \multicolumn{3}{|c|}{ Implicit test } & \multicolumn{3}{|c|}{ Explicit test } \\
\hline & Studied lists & Unstudied lists & Memory score & Studied lists & Unstudied lists & Memory score \\
\hline & $M(M S E)$ & $M(M S E)$ & $M(M S E)$ & $M(M S E)$ & $M(M S E)$ & $M(M S E)$ \\
\hline \multicolumn{7}{|l|}{ List targets } \\
\hline \multicolumn{7}{|l|}{ Korsakoff } \\
\hline $250 \mathrm{~ms}$ & $.40(.04)$ & $.10(.03)$ & $.31(.06)$ & $.28(.08)$ & $.01(.01)$ & $.26(.09)$ \\
\hline $2 \mathrm{~s}$ & $.38(.05)$ & $.22(.05)$ & $.15(.08)$ & $.39(.07)$ & $.04(.03)$ & $.35(.07)$ \\
\hline $5 \mathrm{~s}$ & $.46(.05)$ & $.18(.04)$ & $.28(.05)$ & $.51(.08)$ & $.01(.01)$ & $.50(.08)$ \\
\hline $5 s+$ supp & $.44(.07)$ & $.18(.04)$ & $.26(.07)$ & $.38(.09)$ & $.03(.02)$ & $.35(.10)$ \\
\hline \multicolumn{7}{|l|}{ Control } \\
\hline $250 \mathrm{~ms}$ & $.44(.07)$ & $.10(.03)$ & $.35(.06)$ & $.39(.08)$ & $.00(.00)$ & $.39(.08)$ \\
\hline $2 \mathrm{~s}$ & $.40(.04)$ & $.14(.05)$ & $.26(.06)$ & $.57(.07)$ & $.00(.00)$ & $.57(.07)$ \\
\hline $5 \mathrm{~s}$ & $.51(.07)$ & $.14(.04)$ & $.38(.09)$ & $.67(.06)$ & $.00(.00)$ & $.67(.06)$ \\
\hline $5 s+$ supp & $.43(.04)$ & $.15(.05)$ & $.28(.07)$ & $.60(.08)$ & $.00(.00)$ & $.60(.08)$ \\
\hline \multicolumn{7}{|l|}{ Critical lures } \\
\hline \multicolumn{7}{|l|}{ Korsakoff } \\
\hline $250 \mathrm{~ms}$ & $.42(.06)$ & $.21(.05)$ & $.21(.07)$ & $.36(.07)$ & $.03(.02)$ & $.33(.07)$ \\
\hline $2 \mathrm{~s}$ & $.38(.05)$ & $.31(.07)$ & $.07(.08)$ & $.47(.07)$ & $.03(.02)$ & $.44(.08)$ \\
\hline $5 \mathrm{~s}$ & $.46(.08)$ & $.21(.05)$ & $.25(.11)$ & $.53(.08)$ & $.00(.00)$ & $.53(.08)$ \\
\hline $5 s+$ supp & $.42(.06)$ & $.28(.06)$ & $.14(.07)$ & $.56(.09)$ & $.06(.03)$ & $.50(.10)$ \\
\hline \multicolumn{7}{|l|}{ Control } \\
\hline $250 \mathrm{~ms}$ & $.38(.04)$ & $.22(.04)$ & $.15(.07)$ & $.60(.09)$ & $.01(.01)$ & $.58(.09)$ \\
\hline $2 \mathrm{~s}$ & $.33(.04)$ & $.21(.05)$ & $.13(.06)$ & $.64(.06)$ & $.00(.00)$ & $.64(.06)$ \\
\hline $5 \mathrm{~s}$ & $.47(.09)$ & $.25(.05)$ & $.22(.12)$ & $.69(.09)$ & $.00(.00)$ & $.69(.09)$ \\
\hline $5 s+$ supp & $.36(.04)$ & $.24(.05)$ & $.13(.06)$ & $.65(.09)$ & $.00(.00)$ & $.65(.09)$ \\
\hline
\end{tabular}

Note. Memory scores were obtained by subtracting the proportion of stems completed to targets/lures from unstudied lists (i.e., the baseline completion rate) from the proportion of stems completed to targets/lures from studied lists. Supp $=$ supportive encoding instructions. 
significant for patients $(M=.17), t(88)=3.99, p=.0001$; as well as for controls $(M=.16), t(88)=3.74, p=.0003$. Hence, no direct evidence for a relational encoding deficit in Korsakoff patients with Korsakoff syndrome was obtained, as they showed virtually the same false priming effect as controls did. Contrary to our expectations, no significant effects of Encoding Condition were found (all $F$ s $\leq 1$ ).

\section{Explicit Stem Completion}

A 2 (Group) $\times 4$ (Encoding Condition) $\times 2$ (List Status) mixedfactors ANOVA on the explicit list target completion rates revealed significant main effects of Group, $F(1,88)=6.58$, $M S E=.037, p=.01, \eta_{\mathrm{p}}^{2}=.07$; List Status, $F(1,88)=269.06$, $M S E=.038, p<.0001, \eta_{\mathrm{p}}^{2}=.75 ;$ and Condition, $F(3$, $88)=3.68, M S E=.037, p=.02, \eta_{\mathrm{p}}^{2}=.11$; which were further involved in two significant interactions. Both were in line with what was expected. First, there was an interaction between Group and List Status, $F(1,88)=11.59, M S E=.038, p=.001, \eta_{\mathrm{p}}^{2}=$ .12. As in Experiment 1, pairwise Tukey's tests revealed this effect to be due to a significant difference between patients and controls in the completion rates to studied targets ( $M=.56$ vs. $.39, p=$ $.0003)$, whereas they showed no difference in baseline completion rates to unstudied targets ( $M=.00$ vs. .02). Nonetheless, simple main effects revealed memory scores to be significantly different from zero for patients as well as for controls, in all four conditions (all $p s \leq .001$ ). So, although veridical cued-recall was shown to be higher for controls than for patients, and despite the fact that retrieval instructions discouraged guessing, significant memory scores were obtained in both groups. However, because memory was tested immediately after study, the relatively high performance of the Korsakoff group most likely reflected familiaritybased retrieval.

A second significant interaction was the one between Encoding Condition and List Status, $F(3,88)=3.52, M S E=.038, p=.02$, $\eta_{\mathrm{p}}^{2}=.11$. Although veridical memory was significant in all four encoding conditions (Tukey, all $p \mathrm{~s}<.0001$ ), longer study durations led to higher memory scores than shorter study durations did ( $M=.33, .46, .58, .47$, respectively). Only the difference between the 250-ms and 5-s conditions turned out to be significant, however (Tukey, $p=.009$ ). Planned comparisons on the memory scores of both participants groups revealed that longer study times enhanced Korsakoff patients' performance up to the level of controls. In line with the expectations, patients' memory scores in the 2-s condition were approximately equal to controls' memory scores in the 250 -ms condition $(M=.35$ versus .39$), t(88)=0.37, n s$; and patients' memory scores in the 5-s condition were approximately equal to controls' memory scores in the 2 -s condition $(M=.50$ versus .57), $t(88)=0.62$, $n s$.

A $2 \times 4 \times 2$ ANOVA on the critical lure completion rates revealed significant main effects of Group, $F(1,88)=6.02$, $M S E=.040, p=.02, \eta_{\mathrm{p}}^{2}=.06$; and List Status, $F(1,88)=$ 345.08, MSE = .042, $p<.0001, \eta_{\mathrm{p}}^{2}=.80$; qualified by a significant Group $\times$ List Status interaction, $F(1,88)=10.52$, $M S E=.042, p=.002, \eta_{\mathrm{p}}^{2}=.11$. As for the list targets and as in Experiment 1, this interaction reflected a significant group difference in the proportion of correctly completed lures from studied lists $(M=.65$ versus .48 ; Tukey, $p=.0007)$, whereas the groups did not differ in baseline completion rates $(M=.00$ versus .03$)$.
Nevertheless, as for the veridical memory data, simple main effects revealed false memory scores to be significant for patients as well as controls, in all four conditions (all $p \mathrm{~s} \leq .0001$ ). The relatively high scores in the Korsakoff group could again most likely be attributed to familiarity-based retrieval.

No effects of Encoding Condition were obtained (all $F_{\mathrm{s}} \leq 1$ ). Numerically, however, both control participants and Korsakoff patients with Korsakoff syndrome did show increasingly more false memories when longer study durations were provided (see Table 2). This suggests that more study time does induce (slightly) more false memories. Still, the increase was not as pronounced as the one obtained for veridical explicit memory, and hence nonsignificant. Moreover, Korsakoff patients needed more time to reach the level of controls: Their memory scores in the 5-s condition were approximately equal to memory scores of controls in the 250-ms condition ( $M=.53$ versus .58). In line with the findings of Experiment 1, supportive instructions had no effect whatsoever: There was no difference in false memory between the standard 5-s and the supportive 5-s conditions, for both patients and controls (see Table 2).

\section{Summary}

In the present experiment, list words were presented for $250 \mathrm{~ms}$, $2 \mathrm{~s}$, or $5 \mathrm{~s}$, in order to evaluate whether prolonged processing times would lead to increased levels of false memory in Korsakoff patients and control participants. Moreover, the presence/absence of a group difference in implicit false memory could provide information with regard to the presence/absence of a relational encoding deficit in the patients.

As in Experiment 1, Korsakoff patients' (veridical and false) memory performance was only impaired when tested under explicit retrieval instructions. In addition, when averaged over the different presentation durations, significant false priming was obtained for both patients and controls. Study duration significantly affected veridical memory performance of both groups under explicit retrieval instructions. False explicit memory showed a similar trend, but the effect did not reach significance. The expectation that providing more time to study would increase Korsakoff patients' veridical memory up to the level of controls was confirmed. Also, it was confirmed that the patients' memory following normal encoding was similar to controls' memory following fast/superficial encoding.

\section{General Discussion}

Both of the present experiments were designed to evaluate amnesic and normal implicit and explicit memory for studied words and critical lures in the DRM paradigm. The implicit testing condition was considered especially important because it did not require intentional retrieval of information from the study phase, but rather focused on producing the first stem completion that came to mind. This way, Korsakoff patients' encoding capacities could be assessed without having to consider (explicit) retrieval difficulties. Whereas veridical priming merely requires processing of list words, false priming additionally requires processing of the relationships between the words. Hence, the distinction between the patients' veridical and false memory performance could provide information about the extent to which item-specific and relational memory might be differentially impaired in amnesia.

Based on a pure recollection deficit account, Korsakoff patients could be expected to show diminished (veridical and false) memory 
under explicit retrieval instructions, but normal (veridical and false) priming under implicit retrieval instructions. Following Verfaellie et al. (2005), however, an additional encoding deficit was suspected to be implicated in the results. Therefore, both of the experiments included manipulations to support and aid the patients to process the relational information in an adequate manner. In Experiment 1, encoding instructions were manipulated to investigate the hypothesis that Korsakoff patients might not spontaneously use the appropriate elaborative encoding strategy, whereas Experiment 2 explored the possibility that the patients need more time to process (relational) information.

The study phase in Experiment 1 included not only a standard basic encoding condition, but also a supportive encoding condition, in which participants were encouraged to focus on meaningful relationships between the list words. Based on earlier work suggesting that Korsakoff patients do not spontaneously employ sophisticated encoding strategies (e.g., Cermak, 1979; Cermak et al., 1973, 1998; Phaf et al., 2000; see also Jacoby, 1982), but that they are able to overcome these limitations when given adequate support (Phaf et al., 2000; Van Damme \& d'Ydewalle, 2008), it was hypothesized that only patients in the support condition would show normal false priming. Nevertheless, no priming differences whatsoever were obtained between patients and controls, even in the basic condition. Apparently, Korsakoff patients were able to process the study materials in such a way that allowed for the encoding of both item-specific and relational information. Moreover, encouraging participants to focus on the overlap in meaning of the list words did not affect the level of false memory.

In light of the fact that encoding manipulations generally exert less strong effects on implicit than on explicit memory performance (e.g., Graf \& Mandler, 1984; Richardson-Klavehn, Gardiner, \& Java, 1994), the absence of an effect of instructions on false priming might not be that surprising. However, the finding that supportive encoding instructions also did not increase Korsakoff patients' explicit false memory indirectly implies that no sophisticated, elaborative encoding strategies might be needed in this paradigm. This is in line with the repeated finding of abnormally high levels of DRM false memory in frontal lobe patients (e.g., Budson et al., 2002; Melo et al., 1999), which are characterized by impaired strategic and elaborative encoding (e.g., Gershberg \& Shimamura, 1995; Hirst \& Volpe, 1988; see also Fletcher \& Henson, 2001). It is also in agreement with the results of Experiment 2, revealing significant false memory after extremely short presentation durations (see also Gallo \& Seamon, 2004). Moreover, no effect of relational instructions was obtained in Experiment 2 as well, even when longer presentation durations were used (i.e., $5 \mathrm{~s}$ ).

Due to some important methodological differences, the absence of an effect of encoding instructions cannot be considered as a failure to replicate Chan et al. (2005), who did find relational instructions to increase the likelihood of false memory. Most important, Chan et al. (2005) contrasted a semantic encoding condition to a phonological encoding condition: Encoding was incidental, and participants were merely asked to focus either on the overlap in meaning, or on how the words sounded like. In the current experiments, however, intentional learning instructions were used, and the semantic encoding condition was compared to a basic encoding condition, in which no specific strategy was suggested to the participants. Therefore, the most likely conclusion would be that participants spontaneously attended to the themes of the lists (or the overlap in meaning), even in the basic condition (see Lampinen, Leding, Reed, \& Odegard, 2006, for similar findings). Hence, for patients as well as controls, relational encoding appears to be the default strategy when intentionally studying lists of related words (cf. Hunt \& McDaniel, 1993; McCabe, Presmanes, Robertson, \& Smith, 2004).

In Experiment 2, three different presentation durations were used to investigate whether providing more study time would increase participants' implicit and/or explicit false memory level. Results were similar to Experiment 1, as they revealed that Korsakoff patients' veridical and false memory performance were both only impaired when tested under explicit retrieval instructions. When tested implicitly, there was no memory difference with controls, and significant priming was obtained in both groups. Study duration did not affect veridical or false implicit memory. Explicit memory, on the other hand, did improve when more study time was given, though the effect was only significant for list words and not for lures. Based on earlier work (Van Damme \& d'Ydewalle, 2008; see also Huppert \& Piercy, 1977), it was predicted that providing Korsakoff patients with additional study time (5 s) would enhance their performance up to the level of controls under standard encoding conditions ( $2 \mathrm{~s}$ ). Likewise, based on studies showing that amnesic patients are comparable to healthy participants with weak memory (e.g., Meudell \& Mayes, 1984), Korsakoff patients' performance in the standard condition was predicted to be similar to controls' in the 250-ms condition. For explicit veridical memory, both of these predictions were confirmed. For explicit false memory, however, the patients needed relatively more time, as their performance in the 5-s condition was similar to controls' in the 250 -ms condition.

The effect of encoding duration is in line with experiments manipulating the amount of attentional resources available at study: Dividing attention impairs memory for both item-specific and associative information (e.g., Naveh-Benjamin, Guez, \& Marom, 2003), and can lead to a decrease in both veridical and false recognition performance (e.g., Seamon et al., 1998; but see also Seamon et al., 2003). The finding that patients' explicit memory scores after normal (or even slow) encoding were similar to controls' after fast encoding, suggests that Korsakoff patients might show diminished focal attention during the study phase (possibly due to frontal lobe atrophy; see Oscar-Berman, 1984). Giving them more time then also gives them the opportunity to focus attention in a more efficient manner, leading to heightened semantic activation (cf. McDermott \& Watson, 2001), and hence increased veridical and false memory.

Averaged over the different encoding conditions, Korsakoff patients in both experiments obtained relatively high cued-recall scores for list words as well as critical lures. Observational data and responses on the posttest memory strategies questionnaire revealed that this pattern of findings could be attributed to familiarity-based retrieval, and more specifically to the use of a generate-recognize strategy (e.g., Jacoby, 1998). When asked to use the stems as cues to explicitly retrieve earlier studied words, Korsakoff patients tended to produce whatever words that first popped into mind, followed by a conscious recognition check: The decision to use a word as a response or not was then based on whether the word was recognized as being old or not. Control participants, on the other hand, typically tried to intentionally recollect the studied 
words, or at least tried to generate as many completions as possible before considering the question of whether or not they had seen the stem before. Contrary to the patients, they made use of strategic search processes on the basis of the general themes of the lists, which was also reflected in their responses on the posttest memory strategies questionnaire.

Support for these anecdotal findings can be obtained by comparing patients' and controls' stem completion performance under explicit versus implicit retrieval instructions. As can be seen in Tables 1 and 2, Korsakoff patients' correct completion of targets and lures from studied lists did not differ as a function of retrieval instructions, whereas their baseline completion rates did: As they occasionally chose to reject the automatically generated completion, baseline performance in the explicit condition was lower than in the implicit condition. Hence, the sole difference between the patients' implicit and explicit test performance reflects the recognition process that determined whether a word was kept as a completion or not in the explicit condition. When comparing control participants' implicit and explicit stem completion performance, on the other hand, the data do not only show a decrease in baseline completion, but also an increase in the proportion correctly completed targets and lures from the study phase. Of course, Korsakoff patients' generate-recognize strategy did not purely reflect explicit memory. On the contrary, no explicit retrieval processes need to have been involved, as the automatic generation of a completion could be followed by either familiarity-based or recollection-based recognition (cf. Van Damme \& d'Ydewalle, 2009; see also Yonelinas, 2002; Yonelinas, Kroll, Dobbins, Lazzara, \& Knight, 1998).

To sum up, both of the presented experiments strongly point to deficient explicit recollection of thematic, as well as item-specific, information from the study phase as the main cause of earlier found diminished veridical and false memory levels in amnesic (Korsakoff) patients (e.g., Schacter et al., 1996, 1997). Whereas the patients' memory scores were comparable to controls' when automatic retrieval processes could be used to fulfill the task at hand, both veridical and false memory were impaired when (additional) intentional recollection was required to retrieve the studied information. Nonetheless, it should also be mentioned that these retrieval difficulties could (at least in part) be due to problems during encoding, as providing patients with more study time significantly increased their (veridical) memory scores.

On a more general level, evidence was obtained for an important contribution of unconscious retrieval processes in producing DRM false memories. As stated by Gallo (2006),

one of the ideas emerging from more recent false memory research is that relatively automatic or implicit processes might play a central role in the retrieval of false memories. This link is evident from studies showing that ... nonstudied associates can be primed on implicit tests (even though the subject is not intentionally trying to remember). (p. 249)

Although some researchers have argued that priming for critical lures may be due to explicit contamination during retrieval (e.g., McBride et al., 2006), the present experiments provide strong evidence that it can also be obtained without such contamination: Significant false priming was observed in control participants in both experiments, even though the stem completion test used was specifically designed to minimize the likelihood of contamination by explicit or conscious retrieval processes (cf. McKone \& Murphy, 2000).
Furthermore, as explicit contamination is extremely unlikely among Korsakoff patients, the finding of similar false priming effects in both participant groups strongly points to the conclusion that automatic retrieval processes can suffice to induce DRM false memories. Further studies will need to determine whether this implies long-lasting semantic priming, or rather repetition priming due to conscious thoughts of the critical lures during study (as suggested by Meade, Watson, Balota, \& Roediger, 2007).

\section{Conclusions}

Overall, the present experiments point to the conclusion that the distinction between automatic and controlled retrieval is crucial in determining false as well as veridical memory performance within the DRM paradigm: Korsakoff patients' memory scores were diminished when explicit recollection was required, but not when memory was tested implicitly. Several theories have proposed that the basic deficit in amnesia lies in the formation of new associations between previously distinct elements (e.g., Cohen et al., 1997). Whereas Verfaellie et al.'s (2005) findings suggest that such impaired relational encoding affects performance on both implicit and explicit memory tasks, the present results suggest that it exerts effects only on explicit recollection: Implicit memory for thematic as well as item-specific information was normal, whereas explicit memory was impaired but improved with additional study time. Nevertheless, even the implicit memory results could be fit within relational memory theory, as DRM study words have strong, preexisting relationships, and can therefore not really be considered to be "distinct" elements. On the other hand, priming results are more difficult to reconcile with the argument that amnesic patients show a deficit in memory binding for all sorts of relationships (e.g., Ryan, Althoff, Whitlow, \& Cohen, 2000) or semantic relationships in particular (e.g., Blaxton, 1992; Brunfaut \& $\mathrm{d}^{\prime}$ Ydewalle, 1996).

Of course, it remains possible that patients and controls are processing the DRM lists differently: The absence of a group difference in implicit false memory does not necessarily imply that both groups are doing exactly the same thing during study or are equally attending the relational information. Alternative explanations might be possible and should be tested in future experiments. Moreover, further work is also needed to investigate what caused the difference between Verfaellie et al.'s (2005) and the present results. Because Verfaellie et al. used a mixed amnesic group, whereas only Korsakoff patients were tested in the present study, type of amnesia might be a contributing factor. However, as Verfaellie et al. explicitly compared both types of amnesic patients and found no difference, this seems rather unlikely. A more probable explanation might be the use of intentional versus incidental learning instructions in the study phase. We are currently working on two experiments designed to test this hypothesis.

Supportive encoding instructions affected veridical priming, but had no effect on later memory for critical lures. Also, significant false memory was obtained in both participant groups when lists were studied at a rate of only $250 \mathrm{~ms}$ per word. Together, these findings suggest that effortful, elaborative encoding is not required to obtain false memories in the DRM paradigm. In addition, the fact that significant false priming was obtained in amnesic patients as well as memory-intact controls implies that conscious recollection is not needed as well, and that false memories can be induced through nonintentional, automatic retrieval. 


\section{References}

American Psychiatric Association. (1994). Diagnostic and statistical manual of mental disorders (4th ed.). Washington, DC: Author.

Arndt, J., \& Hirshman, E. (1998). True and false recognition in MINERVA2: Explanations from a global matching perspective. Journal of Memory and Language, 39, 371-391.

Baayen, R. H., Piepenbrock, R., \& Gulikers, L. (1995). The CELEX lexical database [CD-ROM]. Philadelphia: University of Pennsylvania, Linguistic Data Consortium.

Beauregard, M., Chertkow, H., Gold, D., Karama, S., Benhamou, J., Babins, L., et al. (1997). Word priming with brief multiple presentation technique: Preservation in amnesia. Neuropsychologia, 35, 611-621.

Blaxton, T. A. (1992). Dissociations among memory measures in memoryimpaired subjects: Evidence for a processing account of memory. Memory \& Cognition, 20, 549-562.

Brunfaut, E., \& d'Y tasks in Korsakoff and alcoholic patients. Neuropsychologia, 34, 11431150 .

Budson, A. E., Sullivan, A. L., Daffner, K. R., \& Schacter, D. L. (2003). Semantic versus phonological false recognition in aging and Alzheimer's disease. Brain and Cognition, 51, 251-261.

Budson, A. E., Sullivan, A. L., Mayer, E., Daffner, K. R., Black, P. M., \& Schacter, D. L. (2002). Suppression of false recognition in Alzheimer's disease and in patients with frontal lobe lesions. Brain, 125, 2750-2765.

Butters, N., \& Cermak, L. S. (1980). Alcoholic Korsakoff's syndrome: An information-processing approach to amnesia. New York: Academic.

Carlesimo, G. A. (1994). Perceptual and conceptual priming in amnesic and alcoholic patients. Neuropsychologia, 32, 903-921.

Cermak, L. S. (1979). Amnesic patients' level of processing. In L. S. Cermak \& F. I. M. Craik (Eds.), Levels of processing in human memory (pp. 119-139). Hillsdale, NJ: Erlbaum.

Cermak, L. S., Butters, N., \& Gerrein, J. (1973). The extent of the verbal encoding ability of Korsakoff patients. Neuropsychologia, 11, 85-94.

Cermak, L. S., Hill, R., \& Wong, B. (1998). Effects of spacing and repetition on amnesic patients' performance during perceptual identification, stem completion, and category exemplar production. Neuropsychology, 12, 65-77.

Cermak, L. S., Verfaellie, M., Sweeney, M., \& Jacoby, L. L. (1992). Fluency versus conscious recollection in the word completion performance of amnesic patients. Brain and Cognition, 20, 367-377.

Chan, J. C. K., \& McDermott, K. B. (2007). The effects of frontal lobe functioning and age on veridical and false recall. Psychonomic Bulletin \& Review, 14, 606-611.

Chan, J. C. K., McDermott, K. B., Watson, J. M., \& Gallo, D. A. (2005). The importance of material-processing interactions in inducing false memories. Memory \& Cognition, 33, 389-395.

Cohen, N. J., Poldrack, R. A., \& Eichenbaum, H. (1997). Memory for items and memory for relations in the procedural/declarative memory framework. Memory, 5, 131-178.

Deese, J. (1959). On the prediction of occurrence of particular verbal intrusions in immediate recall. Journal of Experimental Psychology, 58, $17-22$.

de Groot, A. M. B. (1980). Mondelinge woordassociatienormen: 100 woordassociaties op 460 Nederlandse zelfstandige naamwoorden [Oral word association norms: 100 word associations to 460 Dutch nouns]. Lisse, The Netherlands: Swets \& Zeitlinger.

de Groot, A. M. B., \& de Bil, J. M. (1987). Nederlandse woordassociatienormen met reactietijden: 100 woordassociaties op 240 substantieven, 80 adjectieven en 80 verba [Dutch word association norms with reaction times: 100 word associations to 240 substantives, 80 adjectives and 80 verbs]. Lisse, The Netherlands: Swets \& Zeitlinger.

Dehon, H. (2006). Variations in processing resources and resistance to false memories in younger and older adults. Memory, 14, 692-711.
Dehon, H., \& Brédart, S. (2004). False memories: Young and older adults think of semantic associates at the same rate, but young adults are more successful at source monitoring. Psychology and Aging, 19, 191-197.

d'Ydewalle, G., \& Van Damme, I. (2007). Memory and the Korsakoff syndrome: Not remembering what is remembered. Neuropsychologia, 45, 905-920.

Faul, F., Erdfelder, E., Lang, A.-G., \& Buchner, A. (2007). G*Power 3: A flexible statistical power analysis program for the social, behavioral, and biomedical sciences. Behavior Research Methods, 39, 175-191.

Fletcher, P. C., \& Henson, R. N. A. (2001). Frontal lobes and human memory: Insights from functional neuroimaging. Brain, 124, 849-881.

Gallo, D. A. (2006). Associative illusions of memory: False memory research in DRM and related tasks. New York: Psychology.

Gallo, D. A., \& Roediger, H. L., III. (2002). Variability among word lists in eliciting memory illusions: Evidence for associative activation and monitoring. Journal of Memory and Language, 47, 469-497.

Gallo, D. A., \& Seamon, J. G. (2004). Are nonconscious processes sufficient to produce false memories? Consciousness and Cognition, 13, $158-168$.

Gershberg, F. B., \& Shimamura, A. P. (1995). Impaired use of organizational strategies in free recall following frontal lobe damage. Neuropsychologia, 13, 1305-1333.

Graf, P., \& Mandler, G. (1984). Activation makes words more accessible, but not necessarily more retrievable. Journal of Verbal Learning and Verbal Behavior, 23, 553-568.

Graf, P., \& Schacter, D. L. (1985). Implicit and explicit memory for new associations in normal and amnesic subjects. Journal of Experimental Psychology: Learning, Memory, and Cognition, 11, 501-518.

Heaton, R. K., Chelune, G. J., Talley, J. L., Kay, G. G., \& Curtiss, G. (1993). Wisconsin Card Sorting Test Manual (revised and expanded). Odessa, FL: Psychological Assessment Resources.

Hicks, J. L., \& Starns, J. J. (2005). False memories lack perceptual detail: Evidence from implicit word-stem completion and perceptual identification tests. Journal of Memory and Language, 52, 309-321.

Hirst, W., \& Volpe, B. T. (1988). Memory strategies with brain damage. Brain and Cognition, 8, 379-408.

Hunt, R. R., \& McDaniel, M. A. (1993). The enigma of organization and distinctiveness. Journal of Memory and Language, 32, 421-445.

Huppert, F. A., \& Piercy, M. (1977). Recognition memory in amnesic patients: A defect of acquisition? Neuropsychologia, 15, 643-652.

Jacoby, L. L. (1982). Knowing and remembering: Some parallels in the behavior of Korsakoff patients and normals. In L. S. Cermak (Ed.), Human memory and amnesia (pp. 97-122). Hillsdale, NJ: Erlbaum.

Jacoby, L. L. (1998). Invariance in automatic influences of memory: Toward a user's guide for the process-dissociation procedure. Journal of Experimental Psychology: Learning, Memory, and Cognition, 24, 3-26.

Johnson, M. K., \& Chalfonte, B. L. (1994). Binding complex memories: The role of reactivation and the hippocampus. In D. L. Schacter \& E. Tulving (Eds.), Memory systems 1994 (pp. 311-350). Cambridge, MA: MIT Press.

Kopelman, M. D. (2002). Disorders of memory. Brain, 125, 2152-2190.

Koutstaal, W., Verfaellie, M., \& Schacter, D. L. (2001). Recognizing identical versus similar categorically related common objects: Further evidence for degraded gist representations in amnesia. Neuropsychology, 15, 268-289.

Lampinen, J. M., Leding, J. K., Reed, K. B., \& Odegard, T. N. (2006). Global gist extraction in children and adults. Memory, 14, 952-964.

Lauteslager, M., Schaap, T., \& Schievels, D. (1986). Schriftelijke woordassociatienormen voor 549 Nederlandse zelfstandige naamwoorden [Written word association norms for 549 Dutch nouns]. Lisse, The Netherlands: Swets \& Zeitlinger.

Lövdén, M., \& Johansson, M. (2003). Are covert verbal responses mediating false implicit memory? Psychonomic Bulletin \& Review, 10, 724 729. 
McBride, D. M., Coane, J. H., \& Raulerson, B. A., III. (2006). An investigation of false memory in perceptual implicit tasks. Acta Psychologica, 123, 240-260.

McCabe, D. P., Presmanes, A. G., Robertson, C. L., \& Smith, A. D. (2004). Item-specific processing reduces false memories. Psychonomic Bulletin \& Review, 11, 1074-1079.

McDermott, K. B. (1997). Priming on perceptual implicit memory tests can be achieved through presentation of associates. Psychonomic Bulletin \& Review, 4, 582-586.

McDermott, K. B., \& Watson, J. M. (2001). The rise and fall of false recall: The impact of presentation duration. Journal of Memory and Language, 45, 160-176.

McKone, E., \& Murphy, B. (2000). Implicit false memory: Effects of modality and multiple study presentations on long-lived semantic priming. Journal of Memory and Language, 43, 89-109.

Meade, M. L., Watson, J. M., Balota, D. A., \& Roediger, H. L., III. (2007). The roles of spreading activation and retrieval mode in producing false recognition in the DRM paradigm. Journal of Memory and Language, 56, 305-320.

Melo, B., Winocur, G., \& Moscovitch, M. (1999). False recall and false recognition: An examination of the effects of selective and combined lesions to the medial temporal lobe/diencephalon and frontal lobe structures. Cognitive Neuropsychology, 16, 343-359.

Meudell, P. R., \& Mayes, A. R. (1984). Patterns of confidence loss in the cued recall of normal people with attenuated recognition memory: Their relevance to a similar amnesic phenomenon. Neuropsychologia, 22, 41-54.

Miatton, M., Wolters, M., Lannoo, E., \& Vingerhoets, G. (2004). Updated and extended Flemish normative data of commonly used neuropsychological tests. Psychologica Belgica, 44, 189-216.

Moritz, S., Woodward, T. S., Cuttler, C., Whitman, J. C., \& Watson, J. M. (2004). False memories in schizophrenia. Neuropsychology, 18, 276-283.

Naveh-Benjamin, M., Guez, J., \& Marom, M. (2003). The effects of divided attention at encoding on item and associative memory. Memory \& Cognition, 31, 1021-1035.

Oscar-Berman, M. (1984). Comparative neuropsychology and alcoholic Korsakoff disease. In L. R. Squire \& N. Butters (Eds.), Neuropsychology of memory (pp. 194-202). New York: Guilford.

Phaf, R. H., Geurts, H., \& Eling, P. A. T. M. (2000). Word frequency and word stem completion in Korsakoff patients. Journal of Clinical and Experimental Neuropsychology, 22, 817-829.

Reitan, R. M. (1958). Validity of the Trail Making Test as an indicator of organic brain damage. Perceptual and Motor Skills, 8, 271-276.

Rey, A. (1964). L'examen clinique en psychologie [Clinical assessment in psychology]. Paris: Presses Universitaires de France.

Richardson-Klavehn, A., Gardiner, J. M., \& Java, R. I. (1994). Involuntary conscious memory and the method of opposition. Memory, 2, 1-29.

Roediger, H. L., III, \& McDermott, K. B. (1995). Creating false memories: Remembering words not presented in lists. Journal of Experimental Psychology: Learning, Memory, and Cognition, 21, 803-814.

Ryan, J. D., Althoff, R. R., Whitlow, S., \& Cohen, N. J. (2000). Amnesia is a deficit in relational memory. Psychological Science, 11, 454-461.

Schacter, D. L. (1987). Implicit memory: History and current status. Journal of Experimental Psychology: Learning, Memory, and Cognition, 13, 501-518.

Schacter, D. L., Verfaellie, M., \& Anes, M. D. (1997). Illusory memories in amnesic patients: Conceptual and perceptual false recognition. Neuropsychology, 11, 331-342.
Schacter, D. L., Verfaellie, M., Anes, M. D., \& Racine, C. (1998). When true recognition suppresses false recognition: Evidence from amnesic patients. Journal of Cognitive Neuroscience, 10, 668-679.

Schacter, D. L., Verfaellie, M., \& Koutstaal, W. (2002). Memory illusions in amnesic patients: Findings and implications. In L. R. Squire \& D. L. Schacter (Eds.), Neuropsychology of memory (3rd ed., pp. 114-129). New York: Guilford.

Schacter, D. L., Verfaellie, M., \& Pradere, D. (1996). The neuropsychology of memory illusions: False recall and recognition in amnesic patients. Journal of Memory and Language, 35, 319-334.

Seamon, J. G., Goodkind, M. S., Dumey, A. D., Dick, E., Aufseeser, M. S., Strickland, S. E., et al. (2003). "If I didn't write it, why would I remember it?" Effects of encoding, attention, and practice on accurate and false memory. Memory \& Cognition, 31, 445-457.

Seamon, J. G., Luo, C. R., \& Gallo, D. A. (1998). Creating false memories of words with or without recognition of list items: Evidence for nonconscious processes. Psychological Science, 9, 20-26.

Smith, S. M., Gerkens, D. R., Pierce, B. H., \& Choi, H. (2002). The roles of associative responses at study and semantically guided recollection at test in false memory: The Kirkpatrick and Deese hypotheses. Journal of Memory and Language, 47, 436-447.

Stadler, M. A., Roediger, H. L., III, \& McDermott, K. B. (1999). Norms for word lists that create false memories. Memory \& Cognition, 27, 494 500 .

Tajika, H., Neumann, E., Hamajima, H., \& Iwahara, A. (2005). Eliciting false memories on implicit and explicit memory tests after incidental learning. Japanese Psychological Research, 47, 31-39.

Tse, C., \& Neely, J. H. (2005). Assessing activation without source monitoring in the DRM false memory paradigm. Journal of Memory and Language, 53, 532-550.

Van Damme, I., \& d'Ydewalle, G. (2008). Elaborative processing in the Korsakoff syndrome: Context versus habit. Brain and Cognition, 67, 212-224.

Van Damme, I., \& d'Ydewalle, G. (2009). Memory loss versus memory distortion: The role of encoding and retrieval deficits in Korsakoff patients' false memories. Memory, 17, 349-366.

van der Made-van Bekkum, I. J. (1973). Nederlandse woordassociatie normen [Dutch word association norms]. Amsterdam: Swets \& Zeitlinger.

van Loon-Vervoorn, W. A., \& van Bekkum, I. J. (1991). Woordassociatie lexicon [Word association lexicon]. Amsterdam: Swets \& Zeitlinger.

Van Zomeren, A. H., \& Brouwer, W. H. (1994). Clinical neuropsychology of attention. New York: Oxford University Press.

Verfaellie, M., Page, K., Orlando, F., \& Schacter, D. L. (2005). Impaired implicit memory for gist information in amnesia. Neuropsychology, 19, $760-769$.

Verfaellie, M., Schacter, D. L., \& Cook, S. P. (2002). The effect of retrieval instructions on false recognition: Exploring the nature of the gist memory impairment in amnesia. Neuropsychologia, 40, 2360-2368.

Woods, R. T., \& Piercy, M. (1974). A similarity between amnesic memory and normal forgetting. Neuropsychologia, 12, 437-445.

Yonelinas, A. P. (2002). Components of episodic memory: The contribution of recollection and familiarity. In A. Baddeley, J. P. Aggleton, \& M. A. Conway (Eds.), Episodic memory: New directions in research (pp. 31-52). Oxford, England: Oxford University Press.

Yonelinas, A. P., Kroll, N. E. A., Dobbins, I., Lazzara, M., \& Knight, R. T. (1998). Recollection and familiarity deficits in amnesia: Convergence of remember-know, process dissociation, and receiver operating characteristic data. Neuropsychology, 12, 323-339. 
Appendix

Summary of Demographic and Neuropsychological Characteristics of Korsakoff Patients in Experiments 1 and 2

\begin{tabular}{|c|c|c|c|c|c|c|c|c|c|c|c|c|c|c|c|c|c|c|c|c|}
\hline \multirow[b]{3}{*}{ Patient } & \multirow[b]{3}{*}{ Sex } & \multirow[b]{3}{*}{ Age } & \multirow[b]{3}{*}{ Educ. } & \multicolumn{11}{|c|}{ Memory } & \multicolumn{6}{|c|}{ Executive functions } \\
\hline & & & & \multicolumn{11}{|c|}{ AVLT (Version 1) } & \multirow{2}{*}{$\frac{\mathrm{TMT}}{\mathrm{B}}$} & \multicolumn{3}{|c|}{ COWAT } & \multicolumn{2}{|l|}{ WCST } \\
\hline & & & & A1 & A2 & A3 & A4 & A5 & Sum & B & A6 & A7 & $\mathrm{A} 8+$ & A8- & & $\mathrm{N}$ & A & $\mathrm{K}$ & $\begin{array}{l}\text { No. of categories } \\
\text { completed }\end{array}$ & $\begin{array}{l}\% \text { persev. } \\
\text { errors }\end{array}$ \\
\hline $01^{\mathrm{a}}$ & $\mathrm{F}$ & 52 & 14 & 3 & 3 & 5 & 5 & 5 & 21 & 3 & 0 & 2 & 5 & 5 & $138^{\prime \prime}$ & 8 & 10 & 11 & 1 & 55 \\
\hline $02^{\mathrm{a}}$ & $\mathrm{F}$ & 59 & 15 & 4 & 4 & 5 & 3 & 5 & 21 & 3 & 0 & 1 & 15 & 12 & $94 "$ & 5 & 8 & 11 & 2 & 37 \\
\hline 03 & $\mathrm{M}$ & 45 & 12 & 3 & 4 & 2 & 4 & 5 & 18 & 2 & 0 & 0 & 9 & 12 & $167 "$ & 6 & 4 & 8 & 0 & 45 \\
\hline 04 & $\mathrm{M}$ & 50 & 12 & 4 & 5 & 5 & 5 & 6 & 25 & 0 & 3 & 1 & 14 & 7 & $235^{\prime \prime}$ & 10 & 12 & 10 & 3 & 42 \\
\hline 05 & M & 42 & 12 & 5 & 7 & 6 & 6 & 4 & 28 & 4 & 1 & 0 & 12 & 15 & $85^{\prime \prime}$ & 9 & 8 & 11 & 6 & 9 \\
\hline 06 & $\mathrm{M}$ & 54 & 13 & 4 & 6 & 9 & 3 & 8 & 30 & 5 & 2 & 1 & 8 & 4 & $91 "$ & 15 & 19 & 22 & 6 & 10 \\
\hline 07 & $\mathrm{M}$ & 53 & 15 & 3 & 5 & 5 & 6 & 6 & 25 & 3 & 4 & 4 & 10 & 3 & $95^{\prime \prime}$ & 17 & 14 & 19 & 6 & 20 \\
\hline 08 & $\mathrm{M}$ & 49 & 12 & 5 & 5 & 4 & 6 & 6 & 26 & 3 & 0 & 0 & 7 & 6 & $84 "$ & 6 & 11 & 12 & 0 & 42 \\
\hline 09 & $\mathrm{M}$ & 51 & 8 & 1 & 2 & 4 & 4 & 5 & 16 & 2 & 0 & 0 & 2 & 1 & $171^{\prime \prime}$ & 1 & 4 & 7 & 3 & 29 \\
\hline 10 & $\mathrm{M}$ & 53 & 16 & 6 & 7 & 8 & 8 & 9 & 38 & 6 & 4 & 5 & 11 & 0 & $38^{\prime \prime}$ & 18 & 17 & 16 & 5 & 13 \\
\hline 11 & $\mathrm{M}$ & 43 & 8 & 3 & 5 & 5 & 6 & 6 & 25 & 2 & 4 & 3 & 12 & 3 & $85^{\prime \prime}$ & 6 & 7 & 14 & 5 & 28 \\
\hline 12 & $\mathrm{~F}$ & 49 & 12 & 2 & 7 & 7 & 8 & 7 & 31 & 4 & 0 & 4 & 13 & 5 & $77^{\prime \prime}$ & 7 & 10 & 16 & 6 & 13 \\
\hline 13 & $\mathrm{M}$ & 51 & 6 & 3 & 4 & 5 & 5 & 5 & 22 & 3 & 0 & 1 & 14 & 13 & $170 "$ & 11 & 8 & 11 & 6 & 13 \\
\hline 14 & $\mathrm{M}$ & 53 & 9 & 4 & 3 & 3 & 4 & 3 & 17 & 2 & 0 & 0 & 0 & 0 & $169^{\prime \prime}$ & 6 & 10 & 6 & 0 & 70 \\
\hline 15 & $\mathrm{M}$ & 56 & 12 & 4 & 3 & 4 & 4 & 5 & 20 & 1 & 2 & 0 & 11 & 14 & $102 "$ & 7 & 8 & 10 & 0 & 20 \\
\hline 16 & $\mathrm{M}$ & 53 & 12 & 2 & 4 & 4 & 3 & 2 & 15 & 1 & 1 & 0 & 9 & 2 & $146 "$ & 8 & 12 & 12 & 4 & 17 \\
\hline 17 & $\mathrm{M}$ & 48 & 12 & 5 & 6 & 8 & 6 & 6 & 31 & 4 & 4 & 1 & 10 & 12 & $76^{\prime \prime}$ & 13 & 16 & 17 & 0 & 38 \\
\hline 18 & M & 68 & 12 & 2 & 5 & 5 & 7 & 6 & 25 & 2 & 4 & 3 & 12 & 7 & $187 "$ & 5 & 5 & 7 & 0 & 36 \\
\hline $19^{\mathrm{a}}$ & $\mathrm{M}$ & 58 & 12 & 3 & 3 & 5 & 5 & 6 & 22 & 2 & 1 & 0 & 3 & 2 & $79^{\prime \prime}$ & 17 & 17 & 12 & 6 & 26 \\
\hline $20^{\mathrm{a}}$ & $\mathrm{M}$ & 44 & 10 & 5 & 6 & 4 & 4 & 4 & 23 & 1 & 3 & 0 & 14 & 18 & $80^{\prime \prime}$ & 9 & 9 & 15 & 4 & 19 \\
\hline 21 & $\mathrm{M}$ & 58 & 8 & 2 & 5 & 4 & 4 & 4 & 19 & 2 & 0 & 0 & 13 & 10 & $132 "$ & 8 & 12 & 14 & 0 & 41 \\
\hline 22 & $\mathrm{M}$ & 43 & 12 & 1 & 3 & 3 & 2 & 4 & 13 & 2 & 0 & 0 & 13 & 7 & $295^{\prime \prime}$ & 2 & 7 & 6 & 0 & 50 \\
\hline 23 & $\mathrm{M}$ & 52 & 14 & 3 & 5 & 7 & 7 & 7 & 29 & 6 & 0 & 4 & 15 & 8 & $129 "$ & 9 & 8 & 12 & 3 & 28 \\
\hline $24^{\mathrm{a}}$ & $\mathrm{F}$ & 51 & 12 & 5 & 5 & 5 & 6 & 6 & 27 & 4 & 0 & 0 & 4 & 0 & $85 "$ & 18 & 22 & 34 & 6 & 14 \\
\hline 25 & $\mathrm{M}$ & 51 & 12 & 4 & 5 & 7 & 6 & 7 & 29 & 5 & 3 & 3 & 15 & 13 & $55^{\prime \prime}$ & 17 & 19 & 19 & 6 & 14 \\
\hline 26 & M & 49 & 8 & 2 & 3 & 3 & 2 & 5 & 15 & 2 & 1 & 0 & 2 & 2 & $125 "$ & 6 & 8 & 7 & 6 & 16 \\
\hline 27 & $\mathrm{M}$ & 59 & 15 & 5 & 5 & 4 & 5 & 4 & 23 & 4 & 1 & 0 & 15 & 16 & $79^{\prime \prime}$ & 15 & 17 & 19 & 4 & 15 \\
\hline 28 & $\mathrm{M}$ & 54 & 12 & 3 & 4 & 5 & 5 & 4 & 21 & 2 & 0 & 0 & 13 & 3 & $157 "$ & 6 & 7 & 10 & 0 & 17 \\
\hline 29 & $\mathrm{M}$ & 61 & 12 & 3 & 3 & 5 & 5 & 4 & 20 & 2 & 2 & 1 & 13 & 17 & $80^{\prime \prime}$ & 8 & 7 & 9 & 6 & 17 \\
\hline 30 & $\mathrm{M}$ & 66 & 12 & 2 & 4 & 5 & 5 & 4 & 20 & 2 & 0 & 0 & 7 & 8 & $200^{\prime \prime}$ & 12 & 7 & 14 & 2 & 50 \\
\hline 31 & $\mathrm{M}$ & 60 & 8 & 4 & 4 & 5 & 4 & 7 & 24 & 3 & 1 & 1 & 12 & 12 & $207 "$ & 8 & 12 & 13 & 0 & 53 \\
\hline 32 & M & 59 & 12 & 2 & 3 & 4 & 4 & 4 & 17 & 4 & 0 & 0 & 12 & 7 & $294 "$ & 6 & 3 & 7 & 6 & 16 \\
\hline $33^{\mathrm{a}}$ & M & 46 & 14 & 6 & 6 & 8 & 8 & 7 & 35 & 6 & 2 & 0 & 2 & 0 & 58 & 12 & 11 & 10 & 6 & 13 \\
\hline 34 & $\mathrm{M}$ & 45 & 12 & 5 & 5 & 5 & 6 & 7 & 28 & 6 & 1 & 0 & 5 & 1 & $44 "$ & 15 & 16 & 20 & 6 & 19 \\
\hline $35^{\mathrm{a}}$ & $\mathrm{M}$ & 58 & $?$ & 2 & 3 & 5 & 7 & 5 & 22 & 1 & 0 & 0 & 14 & 16 & $144^{\prime \prime}$ & 9 & 9 & 15 & 4 & 22 \\
\hline $36^{\mathrm{a}}$ & M & 50 & 12 & 4 & 5 & 3 & 5 & 5 & 22 & 3 & 0 & 0 & 12 & 10 & $124 "$ & 13 & 15 & 15 & 2 & 42 \\
\hline $37^{\mathrm{a}}$ & $\mathrm{F}$ & 47 & 12 & 3 & 3 & 3 & 5 & 6 & 20 & 3 & 0 & 0 & 9 & 11 & $192 "$ & 9 & 7 & 8 & 1 & 20 \\
\hline $38^{\mathrm{a}}$ & $\mathrm{M}$ & 58 & 12 & 2 & 3 & 4 & 5 & 4 & 18 & 0 & 0 & 2 & 10 & 12 & $216^{\prime \prime}$ & 3 & 5 & 6 & 0 & 73 \\
\hline $39^{\mathrm{a}}$ & $\mathrm{M}$ & 58 & 12 & 3 & 4 & 4 & 4 & 5 & 20 & 1 & 0 & 0 & 15 & 14 & $98^{\prime \prime}$ & 4 & 2 & 6 & 6 & 24 \\
\hline 40 & $\mathrm{~F}$ & 64 & 15 & 5 & 6 & 10 & 11 & 11 & 43 & 3 & 10 & 9 & 15 & 5 & $158^{\prime \prime}$ & 4 & 10 & 11 & 2 & 16 \\
\hline 41 & $\mathrm{M}$ & 61 & 9 & 5 & 5 & 8 & 7 & 5 & 30 & 3 & 1 & 1 & 11 & 13 & $95^{\prime \prime}$ & 8 & 10 & 12 & 6 & 26 \\
\hline 42 & $\mathrm{M}$ & 56 & 8 & 1 & 4 & 5 & 2 & 5 & 17 & 3 & 1 & 0 & 11 & 7 & $234 "$ & 1 & 2 & 4 & 3 & 20 \\
\hline 43 & $\mathrm{M}$ & 54 & 12 & 3 & 2 & 3 & 3 & 3 & 14 & 1 & 0 & 0 & 12 & 8 & $455^{\prime \prime}$ & 3 & 2 & 2 & 0 & 25 \\
\hline 44 & $\mathrm{M}$ & 52 & 8 & 1 & 1 & 2 & 1 & 3 & 8 & 1 & 0 & 0 & 0 & 3 & $126^{\prime \prime}$ & 2 & 6 & 9 & 3 & 37 \\
\hline 45 & $\mathrm{M}$ & 46 & 10 & 5 & 6 & 7 & 6 & 10 & 34 & 5 & 4 & 1 & 11 & 0 & 67 & 15 & 17 & 16 & 6 & 10 \\
\hline 46 & $\mathrm{M}$ & 55 & 12 & 3 & 4 & 5 & 4 & 4 & 20 & 3 & 0 & 0 & 14 & 10 & $193 "$ & 5 & 6 & 9 & 0 & 34 \\
\hline 47 & $\mathrm{M}$ & 62 & 9 & 3 & 4 & 4 & 5 & 4 & 20 & 2 & 1 & 1 & 5 & 0 & $209 "$ & 9 & 9 & 13 & 2 & 28 \\
\hline $48^{\mathrm{a}}$ & $\mathrm{M}$ & 56 & 8 & 4 & 5 & 5 & 6 & 4 & 24 & 4 & 2 & 3 & 10 & 10 & $108 "$ & 10 & 10 & 10 & 4 & 28 \\
\hline $49^{\mathrm{a}}$ & M & 49 & 9 & 4 & 5 & 6 & 7 & 5 & 27 & 3 & 0 & 2 & 9 & 6 & $133 "$ & 13 & 10 & 15 & 6 & 11 \\
\hline
\end{tabular}

Note. All patients, except 49, participated in Experiment 2. AVLT $=$ Auditory Verbal Learning Test; TMT $=$ Trail Making Test; COWAT $=$ Controlled Oral Word Association Test; WCST = Wisconsin Card Sorting Test; Educ. = years of formal education; A8+ = recognition hit rate; A8 $-=$ recognition false positives; persev = perseverative; $\mathrm{F}=$ female; $\mathrm{M}=$ male; $"$ = seconds.

${ }^{a}$ These patients also participated in Experiment 1.

Received October 13, 2008 